\title{
Rancang Bangun Mobil Remote Control Pemantau Area berbasis IoT menggunakan ESP 32 Cam
}

\author{
Bayu Fandidarma $^{* 1}$, Ridam Dwi Laksono ${ }^{2}$, Krisna Warih Bintang Pamungkas ${ }^{3}$ \\ 1,2,3 Universitas PGRI Madiun, Indonesia, Fakultas Teknik, Prodi Teknik Elektro \\ e-mail : *1 bayuf@unipma.ac.id, ${ }^{2}$ ridam.dl@unipma.ac.id, ${ }^{3}$ compaq260616@ gmail.com
}

\begin{abstract}
Abstrak
Mobil Remote Control $(R C)$ ini dirancang guna untuk membantu tim relawan dalam mencari korban bencana alam gempa bumi dan juga mengurangi resiko tim relawan jika terjadi sesuatu yang tidak diinginkan. Mobil RC ini dikendalikan oleh IoT dari ESP 32 Cam yang menjadi otak dari sebuah mobil RC ini dari analisis yang di dapatkan mobil bergerak dengan lancar dan tidak ada masalah dan semua fungsi nya berjalan dengan lancar. Driver L298N sebagai penggerak motor dc untuk dapat berjalan maju, mundur, kanan, kiri.
\end{abstract}

Kata kunci - Driver L298N, ESP 32 Cam, IoT, Mobil RC, Motor DC.

\begin{abstract}
This Remote Control $(R C)$ car is designed to assist the volunteer team in finding victims of the earthquake and also to reduce the risk of the volunteer team if something unexpected happens. This RC car is controlled by IoT from the ESP 32 Cam which is the brain of this RC car from the analysis that the car moves smoothly and there are no problems and all its functions run smoothly. L298N driver as a dc motor drive to be able to walk forward, backward, right, left.
\end{abstract}

Keyword - DC Motor, Driver L298N, ESP 32 Cam, IoT, RC Car

\section{PENDAHULUAN}

Indonesia itu secara geografis daerah yang sering terjadi gempa bumi karena indonesia dilalui 3 jalur pertemuan lempeng tektonik yaitu: lempeng Indo-Australia, lempeng Eurasia, dan lempeng Pasific Gempa bumi yaitu bencana alam yang sangat berbahaya dan merugikan bagi masyarakat baik secara material maupun secara non material data dari BMKG (Badan Meteorologi, Klimatologi dan Geofisika). Mencatat bahwa setiap harinya kawasan Indonesia bagian barat pada Pulau Sumatra dapat menghadapi gempa bumi sebanyak 20 kali hingga lebih dalam sehari [1].

Gempa bumi dengan skala di atas 2 skala richter akan mengakibatkan kehancuran beberapa bangunan yang dekat dengan titik gempa, menimbulkan beberapa korban jiwa yang tertimpa bangunan tersebut.

Maka akan mempersulit proses evakuasi tim penyelamat dikarena kan reruntuhan yang tertumpuk sehingga menyebabkan tidak dapat ditelusuri oleh manusia. Jika dipaksakan masuk ke dalam reruntuhan maka akan sangat beresiko bagi tim penyelamat, padahal seharusnya tim penyelamat melakukan penyisiran untuk memantau 
apakah ada korban yang terjebak atau berada di dalam reruntuhan bangunan maupun terowongan [1].

Mobil RC ini dikendalikan dari jarak jauh menggunakan IoT dan dilengkapi dengan kamera ESP 32 Cam agar mobil RC ini dapat bergerak menyusuri area reruntuhan dengan mudah. Adapun cara yang digunakan Untuk pengoperasiannya denga memasukkan IP Address dari ESP 32 Cam ke dalam browser maka akan muncul aplikasi pengendalinya beserta tampilan layar kamera, pemilihan unit pengendali mengunakan smartphone dianggap lebih fleksibel dan tingkat keunggulannya tinggi dari pada mengunakan komputer ataupun laptop.

\section{METODE PENELITIAN}

Pada penelitian ini menggunakan metode pengerjaan secara bertahap atau berurutan dalam pengerjaan nya di mulai dari analisis kebutuhan hingga pengujian alat.

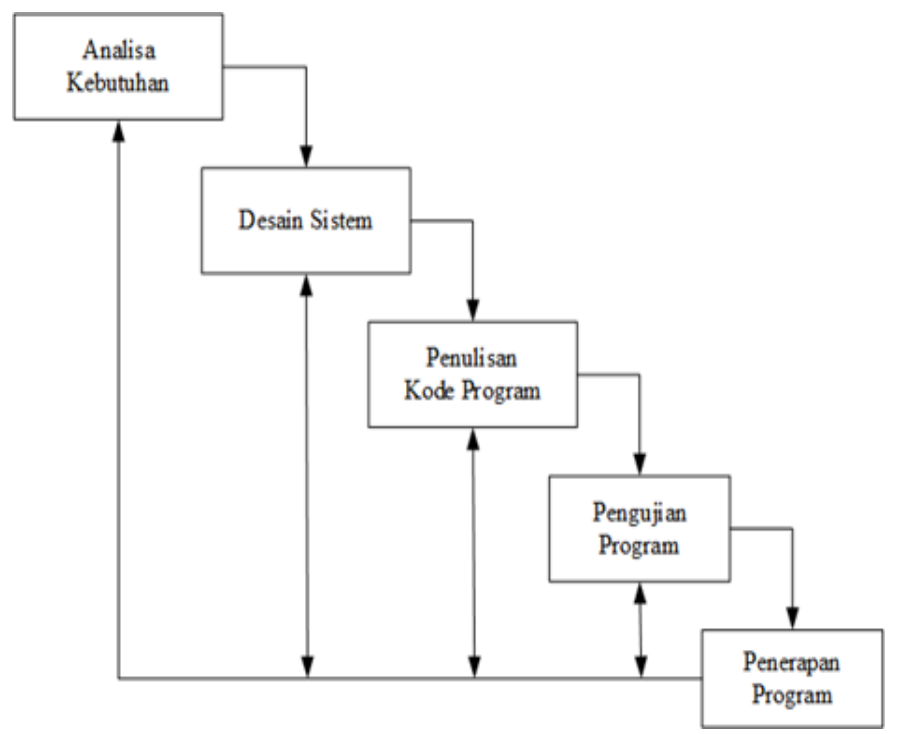

Gambar 1 Metode Penelitian

Rancang bangun yaitu tahap setelah analisis dari siklus pengembangan sistem yang merupakan definisi dari kebutuhan-kebutuhan fungsional. rancangan bangun menggambarkan suatu objek atau sistem dapat berupa penggambaran, perencanaan dan pembuatan sketsa dari beberapa elemen yang terpisah dari satu kesatuan sehingga berfungsi untuk permasalahan yang menyangkut sebuah konfigurasi dari komponen perangkat keras dan perangkat lunak dari suatu sistem.

Rancang bangun yaitu siklus pengembangan sebuah alat yang akan di rancang dan digunakan sebagai kebutuhan khusus untuk menangani suatu masalah. Seperti halnya mobil remote kontrol berbasis IoT menggunakan ESP-32 Cam untuk membantu tim relawanan dalam mencari korban yang selamat pada bencana alam gempa bumi dan dapat menelusuri trowongan dengan memantau keadaan disekitar aman atau tidaknya dimasuki oleh manusia untuk meminimalisir kecelakaan kerja. 


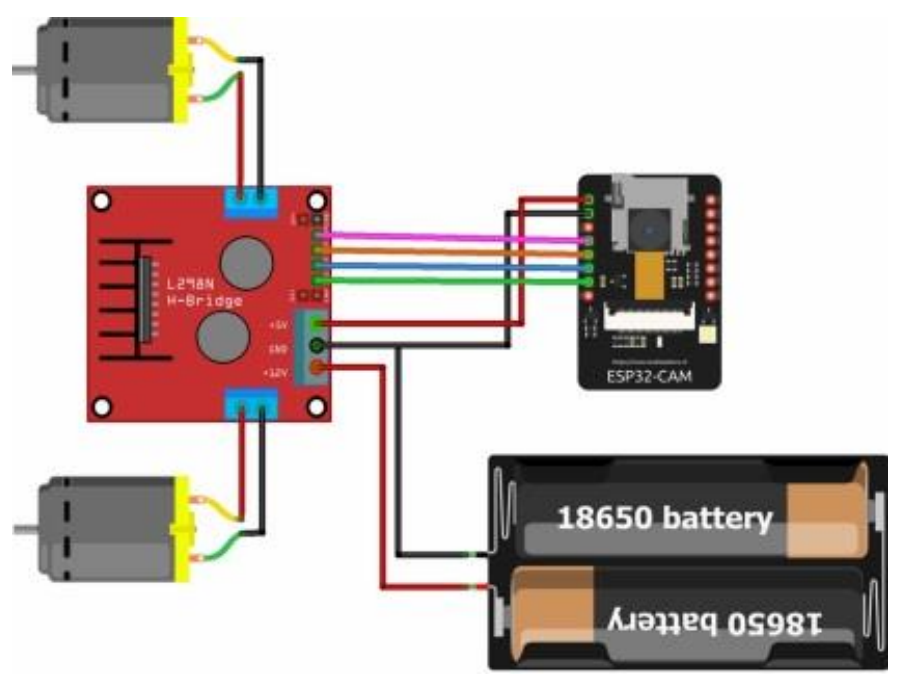

Gambar 2 Pemodelan Sistem Rancang Bangun

\subsection{Mobil Remote Control}

Pengendali jarak jauh atau remot kontrol merupakan alat elektronik yang digunakan untuk mengoperasikan barang elektronik dari jarak jauh. Remot kontrol digunakan sebagai pengendalian perintah tertentu dari jarak jauh. Mobil RC ini dilengkapi sebuah kamera untuk menampilkan hasil penelusuran dan sebagai penunjuk arah pada kondisi gelap mobil ini di fungsikan oleh pihak BPBD dalam mengevakuasi korban bencana alam.

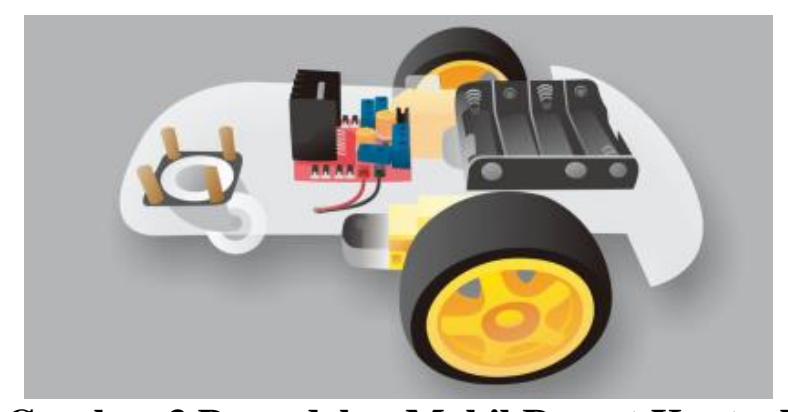

Gambar 3 Pemodelan Mobil Remot Kontrol

\subsection{Pemantau Area}

Pengintai atau pemantau area merupakan alat untuk mengintai, melihat lingkungan yang di rasa berbahaya. Pengintaian merupakan perbuatan mengintai, menelusuri, memantau keadaan di sekitar. Proses untuk mengetahui lingkungan di sekitar dalam melakukan pemantauan apakah lingkungan yang terjadi gempa tersebut berbahaya atau tidak untuk di telusuri.

\section{3. $\quad$ ESP $32 \mathrm{Cam}$}

Mobil RC ini dikendalikan dari jarak jauh menggunakan IoT yang dilengkapi dengan kamera ESP 32 Cam agar mobil remote ini dapat bergerak menyusuri area reruntuhan dengan mudah. Modul AlThinker ESP 32 Cam dilengkapi dengan chip 
ESP32-S, kamera OV2640 yang ukurannya lebih kecil serta dilengkapi slot kartu memory.

Slot kartu micro SD berfungsi untuk menyimpan hasil rekaman yang ditangkap oleh kamera bisa juga untuk menyimpan file. Modul ESP Cam 32 secara luas pada aplikasi IoT. Alat mikrokontroler terdapat pada modul WiFi kamera dalam chip sehingga sangat mendukung dalam membuat sistem aplikasi IoT [2].

\subsection{Internet Of Things}

Internet of Things (IoT) diartikan sebagai jaringan yang dinamis dengan kemampuannya dalam mengkonfigurasi sendiri berdasarkan komunikasi standar. Dimana secara fisik serta virtual memiliki perberbedaan identitas dan karakteristik. Dengan dukungan Cloud Computing, dapat memungkinkan untuk membuka data informasi dari internet, menyimpan atau mengambil data yang terhubung satu sama lain [3].

\section{Hasil Dan Pembahasan}

\subsection{Pengujian Motor DC 1}

Pengujian motor dc ke 1 untuk melihat daya motor setiap naiknya tegangan. semakin cepat motor bergerak maka semakin besar tegangan dan arus yang mengalir ,dengan demikian untuk mengatur kecepatan motor dapat dilakukan dengan mengatur tegangan ke motor.

Tabel 1 Hasil Pengujian Motor DC 1

\begin{tabular}{cccc}
\hline V motor (V) & I motor (A) & Speed (Rpm) & Daya (Watt) \\
\hline 1,0 & 0,24 & 5 & 0,24 \\
2,0 & 0,57 & 11 & 1,14 \\
3,0 & 1,02 & 24 & 3,06 \\
4,0 & 1,19 & 31 & 4,76 \\
5,0 & 1,34 & 42 & 6,7 \\
6,0 & 1,52 & 55 & 9,12 \\
7,0 & 1,66 & 67 & 11,62 \\
8,0 & 1,73 & 76 & 13,84 \\
9,0 & 1,82 & 87 & 16,38 \\
10,0 & 1,98 & 98 & 19,8 \\
11,0 & 2,02 & 109 & 22,22 \\
12,0 & 2,24 & 115 & 26,88 \\
\hline
\end{tabular}

Tabel diatas dilihat beriringan maka kecepatan putaran akan semakin naik karena ada kenaikan tegangan, serta dengan daya dan arus naik. Pada tegangan $12 \mathrm{~V}$ kecepatan adalah $115 \mathrm{rpm}$, arus 2,24 A dan daya 26,88 watt. 


\subsection{Pengujian Motor DC 2}

Penelitian ini menguji motor dc ke 2 guna mengetahui daya motor pada setiap naiknya tegangan. semakin besar tegangan maka semakin cepat motor akan berputar serta semakin besar pula arus mengalir, guna mengatur speed motor dengan cara mengatur tegangan ke motor. Jika tegangan dinaikkan motor semakin bertambah kecepatannya dan jika lebih rendah motor akan berputar lamban.

Tabel 2 Hasil Pengujian Motor DC 2

\begin{tabular}{cccc}
\hline $\begin{array}{c}\text { V motor } \\
(\mathrm{V})\end{array}$ & $\begin{array}{c}\text { I motor } \\
(\mathrm{A})\end{array}$ & $\begin{array}{c}\text { Speed } \\
(\mathrm{Rpm})\end{array}$ & $\begin{array}{c}\text { Daya } \\
(\text { Watt })\end{array}$ \\
\hline 1,0 & 0,26 & 7 & 0,26 \\
2,0 & 0,58 & 14 & 1,16 \\
3,0 & 1,10 & 28 & 3,3 \\
4,0 & 1,22 & 39 & 4,88 \\
5,0 & 1,40 & 52 & 7 \\
6,0 & 1,59 & 65 & 9,54 \\
7,0 & 1,80 & 72 & 12,6 \\
8,0 & 1,83 & 82 & 14,64 \\
9,0 & 1,92 & 93 & 17,28 \\
10,0 & 2,04 & 103 & 20,4 \\
11,0 & 2,22 & 112 & 24,42 \\
12,0 & 2,48 & 117 & 29,76 \\
\hline
\end{tabular}

Terdapat tabel diatas kita lihat berjalannya kecepatan putaran akan naik ketika kenaikan tegangan, serta daya dan arus akan naik. Pada kecepatan motor $117 \mathrm{rpm}$ dengan tegangan $12 \mathrm{~V}$, arus $2,48 \mathrm{~A}$ dan daya 29,76 watt.

\subsection{Pengujian ESP 32 Cam}

Untuk mengetahui kinerja ESP Cam 32 akan diuji terlebih dahulu dengan memasukan program codding kedalam ESP. Codding dibuat untuk ESP guna mengontrol Mobil RC. Algoritma pada program dibuat menggunakan bahasa java kemudian diupload ke board ESP 32 Cam dan melihat reaksinya.

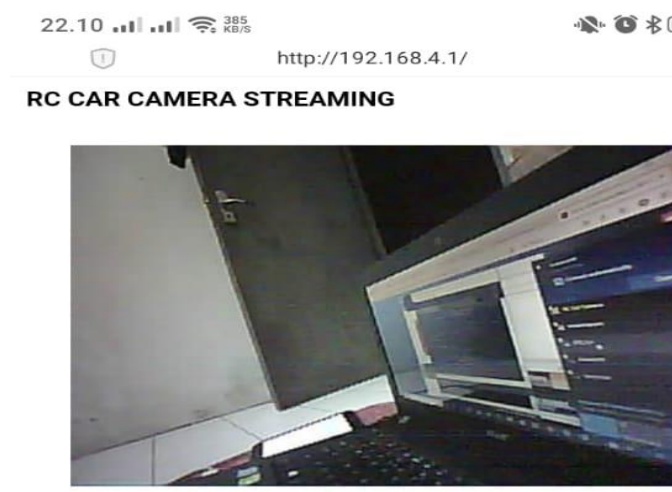

Car Controls

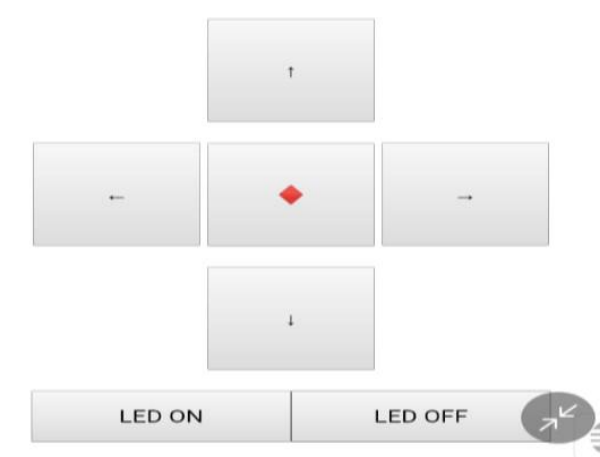

Gambar 4 Hasil Pengujian ESP 32 Cam 


\subsection{Pengujian Sistem Secara Keseluruhan}

Menguji keseluruhan memiliki tujuan guna melihat hasil kerja dari rangkian mobil rc dan aplikasi pada web browser secara keseluruhan. Perancangan sistem Mobil rc berbasis $I o T$ dengan pengujian memberikan input sesuai fungsinya yaitu membantu tim relawan dalam mencari korban bencana alam gempa bumi dan menelusuri lorong yang tidak dapat di lalui oleh tim relawan dan sangat berbahaya jika di masuki paksa oleh tim relawan dengan jaringan Wifi Sebagai berikut langkah menguji robot mobil rc:

1. Hidupkan mobil rc melalui saklar pada robot.

2. Sambungkan ponsel ke dalam wifi ESP 32 Cam.

3. Masukan IP dari ESP 32 Cam ke browser

4. Jalankan Mobil RC untuk menelusuri kolong dan tempat gelap.

5. Pada remote control yang berada di browser akan di tunjukan sebuah kontrol kanan, kiri, atas, bawah serta tombol on/off flash pada ESP 32 Cam

6. Gerak mobil diamati setiap perintah dari remote control.

Dari hasil pengujian dilakukan prosedur diatas dapat disimpulkan Mobil RC berbasis IoT bekerja mengikuti perintah remote control serta berjalan pada tujuan yang sudah diharapkan. Adapun jeda/delay saat dinyalakan flashnya respon robot sedikit lamban, Dapat diatasi dengan berhenti sejenak sehingga antara delay dan gerakan mobil rc tidak kejauhan. Mobil diuji memasuki sebuah kolong. Kondisi gelap mobil bergerak normal. Dengan adanya flash jadi kelihatan terang. Mobil akan mulai melamban pada jarak maksimal terhadap perintah kurang responsif.

Tabel 3. Hasil Pengujian Mobil RC

\begin{tabular}{ccc}
\hline Jarak (meter) & Respon Perintah & Kecepatan \\
\hline 0 & Bekerja Sangat Baik & Normal/Sesuai \\
1 & Bekerja Sangat Baik & Normal/Sesuai \\
2 & Bekerja Baik & Normal/Sesuai \\
3 & Bekerja Baik & Normal/Sesuai \\
4 & Bekerja Baik & Normal/Sesuai \\
5 & Bekerja Baik & Normal/Sesuai \\
6 & Bekerja Baik & Normal/Sesuai \\
7 & Bekerja Baik & Normal/Sesuai \\
8 & Bekerja Baik & Normal/Sesuai \\
9 & Bekerja Baik & Mulai Lambat \\
10 & Kurang respon & Lambat \\
11 & Kurang respon & Lambat \\
12 & Respon Tidak Baik & Lambat dan Delay \\
\hline
\end{tabular}


Dapat disimpulkan respon Mobil RC jika jarak lebih dari 12 meter maka mobil akan bergerak lamban. mobil akan berhenti pada jarak 14 meter. Secara menyeluruh mobil rc bergerak normal dan berhasil dijalankan sesuai harapan. Pada pengujian di kondisi gelap mobil bergerak lancar dan tanpa ada kendala dari mobil tersebut serta ketika mobil di uji di dalam sirkuit yang gelap mobil dapat keluar dari sirkuit dengan lancar dan mudah.

\section{KESIMPULAN}

\subsection{Kesimpulan}

Berdasarkan hasil penelitian dan pembahasan dapat disimpulkan bahwa:

1. Mobil RC ini dapat digunakan di semua medan baik medan yang sulit maupun tidak.

2. Dengan dilengkapinya flash pada ESP 32 Cam mobil mampu bergerak dengan baik pada kondisi gelap.

3. ESP 32 Cam adalah sebuah perangkat pengendali yang sudah dilengkapi dengan camera sangat efisien jika digunakan dalam pembuatan rancang bangun.

4. Mobil RC dapat di oprasikan dengan optimal pada jarak 12 meter.

\subsection{Saran}

Beberapa saran yang dapat diberikan dari hasil penelitian ini diantaranya:

1. Diharapkan untuk penelitian selanjutnya bisa menambahkan komponen yang lain dan berfungsi untuk masyarkat khususnya dalam bencana alam.

2. Disarankan untuk penelitian lebih lanjut mengenai mobil rc menggunakan roda tank atau roda 4.

3. Menambahkan sensor pendeteksi suhu manusia normal.

\section{DAFTAR PUSTAKA}

[1] Isrofi, A., Utama, S. N., \& Putra, O. V. (2021). RANCANG BANGUN ROBOT PEMOTONG RUMPUT OTOMATIS MENGGUNAKAN WIRELESS KONTROLER MODUL ESP32-CAM BERBASIS INTERNET of THINGS (IoT). Jurnal Teknoinfo, 15(1), 45.

[2] Ramadan, D. N., Permana, A. G., \& Hafidudin, H. (2017). Perancangan Dan Realisasi Mobil Remote Control Menggunakan Firebase. Jurnal Elektro Dan Telekomunikasi Terapan, 4(1), 505

[3] Rosa Indriyani. (2014). PENGEMBANGAN ALAT PERAGA FISIKA MELALUI LIMBAH DAUR ULANG BERUPA MOBIL REMOTE CONTROL.

[4] Sugiharto, A. (2019). Rancang Bangun Robot Pengintai Dengan Kendali Androi. Statistical Field Theor, 53(9), 1689-1699. 
[5] Suryadi, N., Marindani, E. D., W, F. T. P., Elektro, J. T., Teknik, F., \& Tanjungpura, U. (2014). Rancang Bangun Robot Tank Yang Dilengkapi Kamera Terintegrasi Dengan Smartphone Android Via Wifi. 2(1), 1-8.

[6] Uma, S., Eswari, R., Bhuvanya, R., Sai, G., Bhuvanya, R., \& Sai, G. (2020). ScienceDirect ScienceDirect IoT based Voice / Text Controlled Home Appliances IoT based Voice / Text Controlled Home Appliances. Procedia Computer Science, 165(2019), 232-238.

[7] Widiyanto, A., \& Nuryanto, N. (2016). Rancang Bangun Mobil Remote Control Android dengan Arduino. Creative Information Technology Journal, 3(1), 50.

[8] Widyawati, E. (2016). Rancang Bangun Aplikasi Kependudukan Berbasis Web Di Desa Kedungrejo Waru-Sidoarjo. Jurnal Manajemen Informatika, 6(1). 